\title{
Teaching and Learning through Technology-mediated Interaction
}

\author{
Ruth Geer and Alan Barnes \\ University of South Australia, Adelaide, Australia \\ ruth.geer@unisa.edu.au
}

Keywords: collaborative learning, communication, interactive, Internet, open flexible learning

\begin{abstract}
In response to the increasing complexity of online environments, educators are seeking ways to utilise evolving technologies for effective teaching and learning. This paper introduces a framework for technology-mediated interaction that attempts to conceptualise the relationship between types of interaction and the suitability of various technologies to support quality learning outcomes. The seven-level model has collaboration as the highest level of meaningful interaction with social interaction, as the foundation level. The quality of learning outcomes at various levels finds their basis in theories of cognitive development and behavioural and social interdependence. The paper provides a guide to sampling such interaction and evidencing quality learning outcomes.
\end{abstract}

\section{INTRODUCTION}

Currently there is accelerated growth in online course delivery and a rapid evolution of Internet based technologies. Foremost among these technologies are those that enable interaction among students and their educators. Establishing a presence in the online education market is a major focus for many universities. With the rollout of Internet technologies into the $\mathrm{K}-12$ sector, online education may become broadly established across all of education. 
Extensive research in the previous decade has shown the capability of computer-mediated communications to engender quality learning (Henri 1991, Newman et al. 1997, Gunawadena et al. 1997). A major thrust of that research was to provide an analysis of the content of the textual discourse and the interactions of the participants; and to identify indicators of cognitive and metacognitive learning that demonstrated the presence of quality learning. With the advent of the World Wide Web, the rise of non-textual interactions and the explosive development of online learning, the major issues have shifted to developing the teaching and learning approaches that can best deploy the new range of technologies in the pursuit of quality learning.

Many factors, such as cultural variables, student characteristics and informal socialising impact on successful teaching and learning through online interactions. A framework is needed that encompasses all these factors, including particularly current and future technologies, and that supports the reflective development of teaching and learning in an online form. Such a framework should not only assist in developing more effective teaching and learning approaches but should enable better evaluation of those approaches. In an effort towards the development of such a framework this paper introduces a model for online interactions and develops techniques for more rapid assessment of the quality of learning generated. These techniques are tested in the context of a current online course.

\section{THE MODEL}

There are a number of factors that influence an effective teaching and learning environment. Interaction and collaboration have been recognised as desirable ingredients in the learning process where students are not only active and supportive, but also interactive (Hiltz 1998, King and Doerfert, 1996). Three essential attributes, which have been identified in an effective learning community, are active learning in the construction of knowledge, positive interpersonal relationships and rich discourse. In collaborative learning communities, students are actively engaged in supporting each other in the development of higher level reasoning strategies, critical thinking, hypothesis formation and reflection. Computer technologies are used to support collaborative and discursive interaction, and build relationships by providing the opportunity to connect and engage learners from many diverse backgrounds. A number of theoretical perspectives, with their foundations in cognitive developmental, behavioural and social interdependence theories (Johnson and Johnson 1996) are guiding the design of courses and our understanding of how students learn. 
Each of the factors or drivers that impact on the effectiveness of the learning environment must be considered and where appropriate, deliberately designed into the instructional program (Berge 1999, King and Doerfert 1996). These drivers, which include cultural variables, student characteristics, informal socialising, prior knowledge, assessment, available technologies and the lecturer's role, impact in varying ways on the types of interaction and associated learning outcomes. One of the difficulties associated with this literature is, that at the time of its writing, many of the contemporary technologies that mediate these interactions, were not in use, and particularly in relation to the web, were not yet conceived. Indeed much of the literature has been concerned with text only communications. There is a need for a new model to help conceptualise how contemporary Internet technologies can promote deep learning and critical thinking resulting in improved learning outcomes.

The following model (Figure 1) of Technology-Mediated Interaction (TMI) incorporates hierarchies of interaction, technologies and learning outcomes together with their influential drivers. It is represented in the shape of a pyramid comprising seven levels. The assumption is, that the higher the level, the greater the quality and frequency of interaction and the higher the learning outcomes that will be achieved. Each level denotes a type of interaction that might be expected in relation to specific teaching and learning approaches. In some approaches students might only move through levels of social interaction, general discussion and topic focussed activities throughout the duration of a course. In other approaches students might be required to reach higher levels, such as cooperative or collaborative levels. In the model the term 'technology-mediated' has been used to characterise interaction through the use of contemporary and future Internet technologies.

Collaboration is surmised as providing the highest level of meaningful interaction and engagement through the use of sophisticated and often specialised multimedia communication tools. It implies working together, yet challenging each other through continual interaction to create meaning, explore topics, construct shared understanding and knowledge, accept group accountability and through a combination of efforts achieve the group goal. Cooperation also implies teamwork and task distribution, but is seen as one step lower down the pyramid where the end result is an aggregation of efforts and individuals are held more accountable. At both levels students work together to support each other. Underlying the ability to cooperate, and ultimately to collaborate, is the ability to show understanding, trust and respect of other learners. 


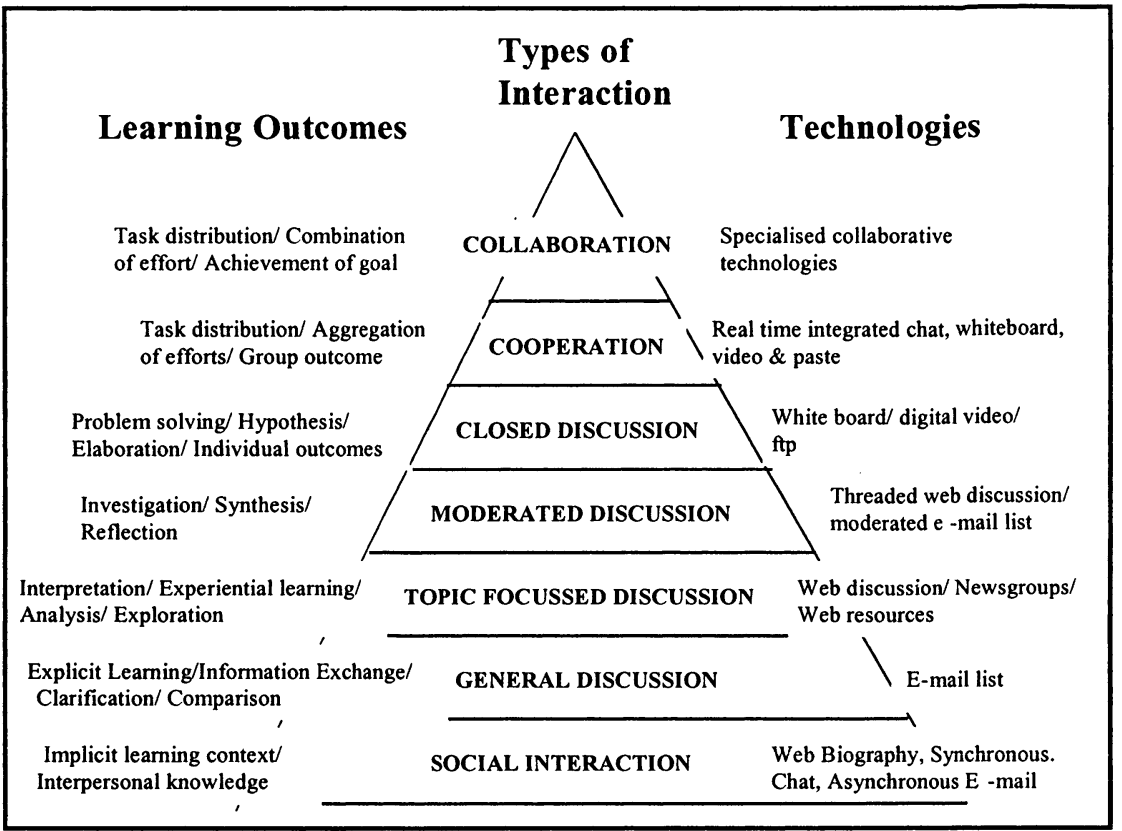

Figure 1. Model of Technology-Mediated Interaction

Interactivity can be defined both in terms of social and content interaction. Social interaction, which forms the foundation on which all levels of interactivity are dependent, is critical in the building of a collaborative learning environment (Jonassen et al. 1999, Hughes and Hewson 1998). It helps students overcome some of their reticence in the exchange of ideas. Interpersonal knowledge helps to create solidarity and commitment and develop standards of conduct for performing group tasks. Web biographies, synchronous chat and asynchronous email can be used to provide opportunities for self-disclosure, an appreciation of social behaviours and the capacity for mutual consideration. The subtleties and specifications of the various levels of interactivity suggest opportunities for varied levels of engagement through the use of appropriate technologies that impact on the learning outcomes.

\section{DILEMMA OF AN ABUNDANCE OF DISCOURSE}

The rise of TMI brings with it a dilemma. Face-to-face conversations have been replaced with interactive digital discourse. Even though these conversations are generally less rich and less frequent than their face-to-face 
counterparts, they exist in overwhelming abundance and are stored permanently by computer systems. What do educators do with this abundance of digital discourse? For educators this dilemma is particularly acute as the discourse calls for educational evaluation. The amount of discourse generated can be overwhelming. The collection of 27 students in this study yielded over 160 postings, many of considerable complexity, in an 8-week term. While many tools exist for the detailed analysis of this discourse, this is impractical for all but the best-resourced educators. The concerned educator needs to find ways to get a sense of the educational quality of the discourse and to be able to intervene strategically and appropriately in the interactions.

A framework for education with TMI needs to be buttressed by effective content sampling that can give confidence that quality learning is occurring. The literature on computer mediated communication indicates that such an analysis (Henri 1991) requires treatment of the participative, social, interactive, cognitive and metacognitive dimensions. It must also be able to identify indicators at the individual and the group level (Gunawardena et al 1997). Table 1, column 1, below, shows a schema of indicators relevant to quality learning, based on the work of Gunawardena and Henri. Sections I and $G$ of the schema have been utilised in the work of Sringam and Geer (2000) to analyse student-led discussion. Section S adds social indicators that are relevant to the pyramid model (Figure 1). Various indicators of this schema will differentially appear in the discourse at various levels of the pyramid model.

Table 1 A Schema for Social Behaviour, Cognitive Development and Interactive Analysis with frequency results of indicators in the discourse

\begin{tabular}{|l|r|r|}
\hline & \multicolumn{1}{|l|}{$\begin{array}{l}\text { Indicator } \\
\text { (f) }\end{array}$} & \multicolumn{1}{l|}{$\begin{array}{l}\text { Section } \\
\text { (f) }\end{array}$} \\
\hline S. Participation and social behaviour & & \\
\hline S1 Individual disclosure & 12 & \\
\hline S1-a Basic introduction & 9 & \\
\hline S1-b Extended revelation & 11 & 32 \\
\hline S1-c Self evaluation & & \\
\hline S2 Social behaviour & 54 & \\
\hline S2-a Courtesy & 0 & \\
\hline S2-b Level of dominance/authority & 14 & \\
\hline S2-c Seeking help & 12 & 80 \\
\hline S2-d Willingness to initiate & & \\
\hline S3 Mutual Consideration & 8 & \\
\hline S3-a Identifying mutual interest & 23 & \\
\hline S3-b Willingness to exchange & 29 & 60 \\
\hline S3-c Valuing others' views & & 172 \\
\hline
\end{tabular}




\begin{tabular}{|c|c|c|}
\hline I. Cognitive behaviour analysis at individual level: & & \\
\hline \multicolumn{3}{|l|}{ I1 Elementary clarification } \\
\hline I1-a Observing/studying a problem & 5 & \\
\hline I1-b Identifying its elements & 25 & \\
\hline I1-c Observing/studying their linkages & 4 & 34 \\
\hline \multicolumn{3}{|l|}{ I2 In-depth clarification } \\
\hline I2-a Analysing a problem & 7 & \\
\hline 12-b Identifying assumptions & 0 & \\
\hline 12-c Establishing referential criteria & 0 & \\
\hline 2-d Seeking out specialised information & 0 & 7 \\
\hline \multicolumn{3}{|l|}{ I3 Synthesis and application } \\
\hline 13-a Drawing primary conclusions & 2 & \\
\hline I3-b Proposing an idea based on links and relevant information & 24 & \\
\hline I3-c Value judgement on relevant solutions & 0 & \\
\hline I3-d Making final decisions and deciding on the action to be taken & 0 & 26 \\
\hline Section I Total & & 67 \\
\hline \multicolumn{3}{|l|}{ G. Interactive behaviour analysis at group level: } \\
\hline \multicolumn{3}{|l|}{ G1 Planning } \\
\hline G1-a Organising work/planning group work/setting shared tasks & 0 & \\
\hline G1-b Initiating activities/setting up activities for group work & 0 & 0 \\
\hline \multicolumn{3}{|l|}{ G2 Sharing/comparing/contributing of information } \\
\hline G2-a Defining and identifying a problem & 7 & \\
\hline G2-b Stating opinions regarding the problem & 24 & \\
\hline $\begin{array}{l}\text { G2-c Asking and answering questions to clarify details of } \\
\text { statements }\end{array}$ & 16 & \\
\hline G2-d Sharing and exchanging knowledge, resources and information & 49 & \\
\hline G2-e Corroborating examples provided by one or more participants & 0 & \\
\hline G2-f Challenging others to engage in group discussion & 2 & \\
\hline G2-g Help and feedback giving & 5 & 103 \\
\hline \multicolumn{3}{|l|}{ G3 Inconsistency of ideas, concepts or statements } \\
\hline G3-a Identifying and stating areas of disagreement & 1 & \\
\hline $\begin{array}{l}\text { G3-b Asking and answering questions to clarify the source and } \\
\text { extend of disagreement }\end{array}$ & 0 & \\
\hline $\begin{array}{l}\text { G3-c Restating the participants' position and advancing arguments } \\
\text { or considerations supported by references }\end{array}$ & 0 & 1 \\
\hline \multicolumn{3}{|l|}{ G4 Negotiation of meaning/co-construction of knowledge } \\
\hline $\begin{array}{l}\text { G4-a Negotiating or clarifying the meaning of terms, areas of } \\
\text { agreement and disagreement }\end{array}$ & 0 & \\
\hline $\begin{array}{l}\text { G4-b Proposing new statements embodying compromise and } \\
\text { co-construction }\end{array}$ & 0 & \\
\hline G4-c Integrating or accommodating metaphors or analogies & 0 & 0 \\
\hline \multicolumn{3}{|l|}{$\begin{array}{l}\text { G5 Testing and modification of proposed synthesis or co-construction } \\
\text { of knowledge }\end{array}$} \\
\hline G5-a Testing against existing knowledge and information & 0 & \\
\hline G5-b Testing against personal experience & 0 & \\
\hline G5-c Testing against formal data collected & 0 & 0 \\
\hline $\begin{array}{l}\text { G6 Agreement statement(s) and application of newly constructed } \\
\text { knowledge }\end{array}$ & & \\
\hline
\end{tabular}




\begin{tabular}{|r|r|r|}
\hline G6-a Summarisation of agreement(s) & 0 & \\
\hline G6-b Application of new knowledge & 0 & 0 \\
\hline Total number of classified utterances & & 104 \\
\hline Total number of posts & 343 \\
\hline Number of students & & 168 \\
\hline & 27 \\
\hline
\end{tabular}

\subsection{The social and participative dimension}

Social exchanges have the potential to alleviate misunderstandings and misinterpretations that can occur through a lack of social cues and face-toface interaction. The social community that is created during the learning process can impact on the nature of the learning activities and the learning outcomes (McLoughlin 1999). While an examination of the participative and social dimension does not add directly to an assessment of quality learning it underpins to varying extents cognitive, and metacognitive processes. Clearly the degree of participation in the discourse can be gleaned from direct inspection of the TMI record. Non-participating students deserve and may need considerable individual attention from the diligent educator. In the study described below reasons for non-participation were mostly structural (e.g. email does not work).

Individual disclosure is often needed to underpin stronger relationships of exchange and mutual consideration. A basic introduction (name, professional interests, background, etc.) provides a basis for discourse. Extended revelation (preferences, feelings, likes, dislikes, etc.) becomes important in sustaining discussion of ideas that begins in the Topic Focussed Level and is more pervasive in the Moderated Discussion Level. The capacity for self-evaluation becomes important as students become more reflective through the Moderated and Closed Discussion Levels. However, it is more critical to task distribution and cooperation on tasks at the Cooperation Level. The extent of revelation and self-evaluation is strongly impacted by cultural and individual characteristics.

Certain social behaviours impact on the types of communications that can be expected in TMI. Courtesy or netiquette is widely recognised as a necessary concomitant of mutually valued discussion (Curtis 1998). Small courtesies lubricate the reciprocal exchange of resources and information starting at the Topic Focussed Discussion Level. The dynamics of dominance and the perceptions of authority come into play in the more complex exchanges of the Moderated Discussion Level and above. These dynamics become critical where there are disagreements over task allocation at the Cooperation Level and where the development of competing ideas is critical to goal achievement especially at the Collaboration Level. Authority issues 
do not arise as much in homogeneous student groups but variegated knowledge, professional experience or status may have communication consequences for some groups. The cultural make-up of a group is also important. For example, the educator may become a highly impacting authority figure in groups of Chinese students. While authority is a socially ascribed quality, dominance/submissiveness may be an individual characteristic of some consequence.

Another important social behaviour indicator is the willingness to seek help and the willingness to initiate. Seeking help becomes first evident in general discussion level as the students come to understand the explicit learning context. It is also important, as the technologies become more complex at the Cooperation and Collaboration Levels. The amount of help sought should be seen as a positive indicator of the clarification of learning goals and processes. The willingness to initiate new ideas, to question and to provoke is increasingly important from the Closed Discussion Level upwards. At these levels lack of willingness to initiate can have educational consequences for individuals. Both indicators are strongly impacted by individual and cultural characteristics.

Mutual consideration is an important reinforcer of the free flow of ideas and criticism, and is characteristic of Closed Discussion Levels and above. The development of mutual consideration can begin at the Social and General Discussion Level through identifying mutual interests and dispositions. The willingness to exchange information is evident at the general discussion level and generally speaking its absence has a strong impact on the lack of exchange of opinions, ideas and inventions at higher levels. The capacity for valuing the views of others becomes important in the Cooperative Level but is critical to successful collaboration.

\subsection{Mapping indicators to levels of interaction}

In the spirit of providing for more rapid evaluation of student discourse a map of cognitive, social and behavioural indicators to levels of TMI is presented below. It is convenient to consider the level of interaction at which the indicator is first and most naturally likely to appear. It is instructive to consider where an indicator is a critical condition for a certain interactive type.

Column three can be used as a guide to quick investigation of the discourse. The absence of the indicators in column four in the discourse may signal that educational intervention is necessary. 
Table 2. Sampling Guide for types of interactivity

\begin{tabular}{|c|c|c|c|}
\hline $\begin{array}{l}\text { Pyramid } \\
\text { Level }\end{array}$ & Type of Interactivity & $\begin{array}{l}\text { Likely First Instance } \\
\text { of Indicator }\end{array}$ & $\begin{array}{l}\text { Critical Indicator for } \\
\text { Interactive Type }\end{array}$ \\
\hline Level 7 & Collaboration & G1b, G5a-c, G6a-b & $\begin{array}{l}\text { S3c, G1b, G2e-f, G3a-c, } \\
\text { G4a-b, G6a }\end{array}$ \\
\hline Level 6 & Cooperation & $\begin{array}{l}\text { I3d, G1a, G2e-f, G3a-c, } \\
\text { G4a-c }\end{array}$ & $\begin{array}{l}\text { S1c, S2b, I2c, 12d, I3d, } \\
\text { G1a, G2a-d }\end{array}$ \\
\hline Level 5 & Closed Discussion & $\mathrm{I} 2 \mathrm{c}, \mathrm{I} 2 \mathrm{~d}, \mathrm{G} 2 \mathrm{a}-\mathrm{d}$ & $\mathrm{S} 2 \mathrm{c}, \mathrm{S} 2 \mathrm{~d}, \mathrm{I} 3 \mathrm{a} \mathrm{I} 3 \mathrm{c}$ \\
\hline Level 4 & Moderated Discussion & $\mathrm{I} 1 \mathrm{c}, \mathrm{I2b}, \mathrm{I3a}, \mathrm{I3c}$ & $\mathrm{I} 1 \mathrm{c}, \mathrm{I} 2 \mathrm{~b}$ \\
\hline Level 3 & $\begin{array}{l}\text { Topic Focussed } \\
\text { Discussion }\end{array}$ & $\mathrm{I} 1 \mathrm{a}, \mathrm{I1} \mathrm{b}, \mathrm{I} \mathrm{a}, \mathrm{I} \mathrm{b} \mathrm{b}, \mathrm{G} 2 \mathrm{~g}$ & S2a, I1 a, I1b, I2a, I3b \\
\hline Level 2 & General Discussion & $\mathrm{S} 2 \mathrm{~b}, \mathrm{~S} 2 \mathrm{c}, \mathrm{S} 3 \mathrm{~b}, \mathrm{~S} 3 \mathrm{c}$ & S3b \\
\hline Level 1 & Social Interaction & $\mathrm{S} 1 \mathrm{a}, \mathrm{S} 2 \mathrm{a}, \mathrm{S} 3 \mathrm{a}$ & S1a \\
\hline
\end{tabular}

\subsection{The study}

Two groups of students taking the Internet in Education course in the Graduate Certificate in Educational Computing (University of South Australia) were the subjects of this study. The groups were chosen at random from the 4 groups taking the course. The expected sequence of interaction types in this subject were Social Interaction in week 1, General Discussion in week 2-4, Topic Focussed Discussion in week 3-8. The technologies used were email list, threaded web discussion and web resources. Students identified a topic of interest concerning the use of the Internet in education and posted a brief outline of its educational merits. In addition students were required to post peer critiques of the outlines to the discussion group. The manipulation of the assessment driver introduced an element of cooperative input in the preparation of final papers for assessment.

Table 1 shows the instances of occurrences of indicators in the aggregated discourse generated by the two groups. Generally the frequency of indicators was consistent with the occurrence identified in the Table 2 above. The indicators in G2 were prevalent in the discourse due to the use of the assessment as a driver to establish an element of cooperation.

\section{CONCLUSION}

A pyramid model for Technology-Mediated Interaction has been presented which together with the major drivers and 'rapid' evaluative mechanisms provides a tentative framework for developing and for informing teaching and learning in an online context. While the impact of the assessment driver, within the given teaching and learning approach is evident from the case study, much more needs to be done to characterise this 
and other drivers. A 'rapid' evaluation mechanism that can provide greater confidence in the quality of learning has been presented. The extent to which such confidence can be quantified will be examined in a forthcoming paper. Evaluation of non-text interactions will be the subject of future research.

\section{REFERENCES}

Berge, Z. (1999) Interaction in post secondary web-based learning. Educational Technology, 39 (1), pp. 5-11.

Curtis, D. D. (1998) Guidelines for online interactions. [http://www.roma.unisa.edu.au/1 1565/onlineinteract.htm] 28.6.1998.

Gunawardena, C. N., Lowe, C. A., and Anderson, T. (1997) Analysis of a global online debate and the development of interaction analysis model for examining social construction of knowledge in computer conferencing. Journal of Educational Computing Research, 17 (4), pp. 397-431.

Henry, F. (1991) Computer conferencing and content analysis. In Collaborative Learning through Computer Conferencing, A. R. Kaye (ed), Springer-Verlag, Heidelberg.

Hiltz, S. R. (1998) Collaborative learning in Asynchronous Learning Networks: Building learning communities. [http://eies.njit.edu/ hiltz/collaborative_learning_in_asynch.htm] 24.8.1999.

Hughes, C. and Hewson, L. (1998) Online Interactions: Developing a neglected aspect of the virtual classroom. Educational Technology, vol. July-August, pp. 48-55.

Johnson, D. W. and Johnson, R. T. (1996) Cooperation and the use of technology. In Handbook of Research for Educational Communication and Technology, D. Jonassen (ed), Macmillan Library Reference, New York, USA, pp. 1017-1044.

Jonassen, D. H., Peck, K. L. and Wilson, B. G. (1999) Learning with Technology: A Constructivist Perspective, Merrill, Upper Saddle River, New Jersey.

King, J. L. and Doerfert, D. L. (1996) Interaction in the distance education setting. [http://www.ssu.missouri.edu/ssu/Aged/NAERM/s-e-4.htm] 7.9.1999.

McLoughlin, C. (1999) Culturally responsive technology use: developing an on-line community of learners. British Journal of Educational Technology, 30 (3), pp. 231-243.

Newman, D., Johnson, C., Webb, B. and Cochrane, C. (1997) Evaluating the quality of learning in computer supported co-operative leaming. Journal of the American Society for Information Science, 48 (6), pp. 484-495.

Sringam, C. and Geer, R. (2000) An Investigation of an instrument for analysis of student-led electronic discussions. In Learning to Choose, ASCILITE 2000 Conference Proceedings, Coffs Harbour, NSW, Dec. 2000, pp. 81-91.

\section{BIOGRAPHY}

Ruth Geer is a lecturer in educational computing; her research focuses on drivers of collaborative interactivity in internet-based courses and their learning outcomes. Dr. Alan Barnes is a senior lecturer in the School of Education (Magill), with an extensive research background in use of ICT. 